\title{
The Primacy of Bilinguals and Trilinguals College Students' Views on Reading and Language Learning
}

\author{
Negmeldin Alsheikh ${ }^{1}$ \\ ${ }^{1}$ Department of Curriculum and Methods of Instruction, College of Education, United Arab Emirates University, \\ United Arab Emirates \\ Correspondence: Negmeldin Alsheikh, Department of Curriculum and Methods of Instruction, College of \\ Education, United Arab Emirates University, United Arab Emirates. Tel: 971-3713-6253. E-mail: \\ nalsheikh@uaeu.ac.ae
}

Received: October 27, 2017 Accepted: December 15, 2017 Online Published: December 18, 2017

doi: $10.5539 /$ elt.v11n1p150

URL: http://doi.org/10.5539/elt.v11n1p150

\begin{abstract}
This study aimed at understanding the essence of reading and language learning by bilinguals and trilinguals college students. The study is based on data from two separate yet related studies that were completed. The study used interviews as a qualitative means to glean the views of Arab bilinguals $(n=10)$ and African trilinguals $(n=3)$. The study is based on symbolic interactionism approach to incorporate a focus on intersubjective realities of bilinguals and trilinguals, openness to bilinguals and multilinguals' experiences and a search for invariant indispensable meaning in their descriptions of their bilingualism and multilingualism. In a very important sense, this study attempted to get beyond the immediacy of an experienced world in order to articulate the pre-reflective level of lived-world of bilinguals and trilinguals. The preliminary results of this study revealed that both bilinguals and trilinguals viewed reading as an establish tool for gleaning meaning. On the other hand, trilinguals viewed language from a larger intersubjective scope where the shared common understandings through ongoing symbolic interaction with the others. The trilingual also assigned more spatial perspectives, more metalinguistic awareness of reading and languages learning than the bilinguals.
\end{abstract}

Keywords: bilinguals, trilinguals, Arabs, Africans, reading, language learning

\section{Introduction}

Bilingualism and multilingualism in the age of globalism are a panacea for bringing people and nations together. Understanding bilinguals and multilinguals at a personal level is vital to understand how they view themselves, their language use and their reading and learning. As Grosjean (1982) puts it "bilingualism is a fact of life, as normal as sleeping and eating", p. 268). Many researchers underscore the need to study bilinguals and multilinguals by unleashing different methods to fathom full range of its trajectories and complexities including their personal beliefs, policies, practices, values, norms, realities and expectations (García \& Lin, 2016; Hakuta, 2011; Pease-Alvarez, 2002; Pease-Alvarez \& Hakuta, 1992). Recognizing and thinking about relationships among languages could open infinite possibilities for devising systems of linguistic expression on the mental or intellectual plane as illustrated by Benjamin Whorf (Carroll, 1956)

The possibilities open to thinking are the possibilities of recognizing relationships and the discovery of techniques of operating with relationships on the mental or intellectual plane, such as will in turn lead to ever wider and more penetratingly significant systems of relationships. These possibilities are inescapably bound up with systems of linguistic expression. The story of their evolution in man is the story of man's linguistic development - of the long evolution of thousands of very different systems of discerning, selecting, organizing and operating with relationships (Carroll, 1956, p. 84)

\subsection{Theoretical Framework}

To reach a better understanding of bilinguals and trilinguals a better theoretical clarity is needed. The basic theoretical framework that works better for our purpose is symbolic interactionism description of consciousness. Symbolic interactionism postulated that human beings are active, reflective agents who construct their lives (Prus, 1996). In this sense, we don't study bilinguals and trilinguals as others, by entering their world we intermingle with them in order to fathom their "obdurate realities" (Prus, 1996) by understanding their world as 
we try hard to establish an understanding of our reality. Thus meaningful interaction, self-reflectivity and mindful behavior could be emanating from the juncture of language, culture and intersubjectivity. The Symbolic interactionism fits perfectly with the bilinguals and trilinguals' language experiences because language acquisition and use is at the core of human Intersubjectivity (Prus, 1996).

Language provides the basis on which people establish common (community) understanding and it is through ongoing (symbolic) interaction with the other that one may establish more precise levels of intersubjectivity or more comprehensive understandings of the viewpoints of the other as well as more intricate sense of self (Prus, 1996, p. 11).

Some scholars argued that bilinguals assume different identities when changing registers, contexts, interlocutors, or interactional aims (Baker, 2011; Grosjean, 1982; Pavlenko, 2006; Pavlenko, 2002). Yet, how do bilinguals and multilinguals view themselves as readers and strategic language learners? Aside of being a linguistic phenomenon, the languages that bilinguals and multilinguals learned and speak can be often considered as a system of belief. What bilinguals and multilinguals usually believe, write, say, value about the confines, borders and boundaries between and among languages are so important and vital on how they view the languages they learn; the value that the bilingual and multilinguals perceives is vital because it compels us to meditate and negotiate their metalinguistic stance and it opens doors for researchers to reach a transcendental understanding of the languages they learned and the different realities they establish (Hadi-Tabassum, 2006).

\subsection{Bilingualism vs. Trilingualism}

Some researchers indicated that research in trilingualism is carried out in the theoretical vein of bilingualism and there are no real efforts to delimit trilingualism in its own right (Aronin, \& Hufeisen, 2009; Hoffmann, 2001; Njurai, 2016). Although certain salient similar features could be noticed in both bilinguals and trilinguals, there are some distinct features that could be observed in trilingualism. Some bilinguals' practices could serve as a venue for exploring and understanding possible essential features of trilinguals' practices and competence. For example, Aronin, and Hufeisen (2009) indicated that multilingualism is complex in different respects and aspects. In a very important sense, the complexity of multilingualism is increasingly greater than that of bilingualism. While this evidence is not conclusive, the findings gleaned from different studies could convince us that in many different important ways an additional, third language acquisition is distinct from second language acquisition (Aronin, \& Hufeisen, 2009). A bilingual or a multilingual could come to different realizations about his bilingual or multilingual's self and his different persona in his journey to acquire and learn other languages (Lvovich, 1997). Hence different intersubjective issues emanate through the evolution of thousands of different marked systems of discriminating, choosing, shaping, organizing and operating with relationships as alluded to earlier by Benjamin Whorf.

When Grosjean (1982) surveyed some of bilinguals and multilinguals; the bilinguals indicated that there was "no inconvenience" in being bilinguals". The study also showed that the inconvenience was pertinent to a weaker language, code switching and language mixing. The advantages of bilinguality according to the bilinguals are: communication and bond with other bilinguals, communicating with two cultures, give double perspectives on the world, communicate with more people. The multilinguals see the advantage as: broaden their human scope, communicate with different types of people, read a greater variety of books, each language has different logic, aware of linguistic problems, add different manner and means of expressions, see the beauty of languages, add spatial spectrum in human experience, no boredom, open mindedness, personal pride, greater stature in work and job opportunities (see Grosjean, 1982, pp. 268-272). This view is very close to what Bakhtin described as a heteroglossia. A Heteroglossia is "a way of conceiving the world as made up of a rolling mass of languages, each of which has its own distinct formal markers" (Holquist, 1990, p. 69). In essence Bakhtin's view is similar to what bilinguals and trilingual try to achieve when they read in a second, a third or a fourth language. They usually try to make sense of their reading in that language and they become very attentive to the act of reading. This study is inspired by earlier studies on nonnative speakers specifically Arab native speakers and Spanish native speakers and African multilinguals (see Alsheikh, 2014; Alsheikh, 2011; Alsheikh \& Mokhtari, 2011; Alsheikh, 2009; Garcia, 1991; Jimenez, Garcia, \& Pearson, 1996; Jimenez, Garcia, Pearson, 1995; Jimenez, Garcia, \& Pearson, 1994).

\section{Methodology}

This study used symbolic interactionism method which according to Blumer, (1986) rests on three simple premises. The first premise is that human beings act toward meaningful things on the basis of their implications; the second premise is that the meaning of such things is derived from, or arises out of the social interaction; and the third premise is that these meanings are handled in, and modified through an interpretative process used by 
the person in dealing with the things he encounters (Blumer, 1986, p. 2). The basic ideas "root images" are primarily depicting human groups or societies, social interaction, objects, the human being as an actor, human action and the interconnection of the lines of action (Blumer, 1986, p. 6).

\subsection{Interviews}

According to Kvale (1996), Kvale (2008) and Kvale and Brinkmann, (2009), the qualitative interview is a construction site of knowledge. The knowledge generated by interviews is related to five features of a postmodern construction of knowledge: the conversational, the narrative, the linguistic, the contextual, and the interrelational nature of knowledge. The interviewee, in this study articulated their modes of thinking, their activities, and their experiences with and reactions toward bilingualism and trilingualism. In conducting interviews, the following seven steps suggested by Kvale (1996) were followed: thematizing, designing, interviewing, transcribing, analyzing, verifying, and reporting. According to Kvale (1996), there are five main approaches to interview analysis; these five approaches are: categorization of meaning, condensation of meaning, structuring of meaning through narratives, interpretation of meaning, and ad hoc methods for generating meaning. The first step: meaning condensation entails an abridgement of the meaning expressed by the interviewees into shorter formulations, i.e. the long statements are compressed into briefer statements in which the main sense of what is said is rephrase in a few words. The second step: meaning categorization implies that the interview is coded into categories; long statements are reduced to simple categories such as "+" or "-" indicating occurrence and non-occurrence of the phenomenon. The third step: narrative structuring entails bring out meaning. The fourth step: meaning interpretation goes beyond a structuring of the manifested meaning of the text to a deeper and more or less speculative interpretation of the text. The last step: generating meaning through ad hoc methods is an "eclectic approach" (Kvale, 1996, p. 191). by using a sophisticated textual or quantitative methods. The outcome of this meaning can be in words, in number, in figures and flow charts, and in their combinations. The interview consists of fifteen questions, which were adopted from Jiménez, García and Pearson (1995).

\subsection{Research Question and Sub-questions}

How do bilinguals and multilinguals view their reading and language learning?

1) How do bilinguals and multilinguals view themselves as readers in multiple languages?

2) How do bilinguals and multilinguals view the reciprocal relationships among two or multiple languages?

3) How do bilinguals and multilinguals view themselves as strategic readers and learners?

\subsection{The Participants}

This study included 13 participants, the Arab bilinguals $(n=10)$ and African trilinguals $(n=3)$. In the following paragraphs, a descriptive profile for each group and individuals is provided. All the participants in this study come from one of the Midwestern universities.

\subsection{The Arab Bilinguals' Profile}

The Arab bilinguals $(n=10)$ in this study come from different Arab countries. For all the participants, Arabic is the first language and English is the second language. All the participants speak, read and write Arabic and English with varying degrees of proficiency. The participants also consider themselves to be most fluent in Arabic followed by English; they spent eight to twelve years in studying English. The following paragraphs give a brief description about the participants.

Maha: Maha has lived for thirteenth year in the United States. She is pursuing a bachelor's degree in secondary education. She is 32-year-old and her home country is Tunisia.

Samir: Samir has lived for three years in the United States, pursuing his bachelor degree in engineering. He is 28-year-old and his home country is Libya.

Khalid: Khalid has lived for three years in the United States, pursuing his doctorate degree in English. He is 34-year-old and his home country is Saudi Arabia.

Amir: Amir has lived for ten years in the United States, pursuing his master's degree in electrical engineering. He is 35 -years-old and his home country is Jordan.

Azza: Azza has lived for eight years in the United States, pursuing her doctorate degree in special education. She is 34-years-old and her home country is Sudan.

Naser: Naser has lived for six years in the United States, pursuing his doctorate degree in microbiology. He is 35 -year-old and his home country is Egypt. 
Ali: Ali has lived for nine years in the United States, pursuing his doctorate degree in microbiology. He is 40-year-old and his home country is Sudan.

Amina: Amina has lived for five in the United States, pursuing her bachelor degree in civil engineering. She is 26 years old and her home country is Egypt.

Faisal: Faisal has lived for fourteen years in the United States, pursuing his doctorate degree in veterinary medicine. He is 44-year-old and his home country is Sudan.

Mahmoud: Mahmoud has lived for eight years in the United States, pursuing his master's degree in mechanical engineering. He is 25 -year-old and his home country is Palestine.

\subsection{African Trilinguals' Profile}

There were three multilinguals, two of the three participants come from Niger and one from Cameron. For all the participants, Hausa is the first language, French is a second language and English is the third language. All the participants speak, read and write Hausa, French, English with varying degrees of proficiency. The participants consider themselves to be fluent in all the languages and they speak other languages in West Africa. Additionally, they know some Arabic and memorize many chapters from the Quran. They spent eight to twelve years in studying their languages. The following paragraphs give a brief description about the participants.

Amadou: Amadou has lived for ten years in the United States, pursuing his doctorate degree in microbiology. He is 44-year-old and his home country is Niger.

Imarou: Imarou has lived for eight years in the United States, pursuing his master's degree in economics. He is 35 -year-old and his home country is Cameroun.

Mahamadou: Mahamadou has lived for five years in the United States, pursuing his bachelor's degree in economics. He is 25 -year-old and his home country is Niger.

\section{Results}

\subsection{Arabic Bilinguals and African Trilinguals Views on Reading}

\subsubsection{The Essence of Reading Experience}

The 10 Arab bilinguals came from different disciplines, different countries, and different levels of education both graduate and undergraduate. To keep the names anonymous, the researcher assigned pseudonyms for the interviewees. The interview questions were aimed at gathering information about the essence of reading and reading in general for the first five questions. The first five questions that were asked: How do you define reading? Why do people read? What constitutes a good reader? What does a person need to know and be able to do to be a good reader? What is the difference between a person who is a good reader from someone who is not? These five questions are general questions about reading which could be asked to monolinguals, bilinguals, and trilinguals alike; they reflect people general understanding of reading. The aim of these questions is to see how Arab bilinguals view the act of reading. For example, the first question is search for definition of reading according to Arabic bilinguals and the African multilinguals; the second question is about why people, in essence, read? This question will instigate the reasons why people read in general. The third question was aimed at getting an image of the ideal reader according to the Arab bilinguals; the fourth question was about what a person need to know and be able to do to be a good reader, and the fifth question is aimed at making contrast between a good reader and a poor reader.

\subsubsection{Reading as an Active and Decoding Process}

Most of the 10 Arab bilinguals viewed reading as a decoding process and as an active process of activating prior knowledge. They regard reading as a process a reader go through to acquire new written information, the ability to decode words with optimal understanding and reflection. For example, Amina, Mahmoud and Khalid reflected this view:

Amina: Visualizing of words and making sense of these words

Khalid: Reading is basically, what in the text and what is in our mind, all the time we activate our prior knowledge to understand texts

Mahmoud: Reading is to go over some subjects and try to get a general idea about it, if it is general subject, however if it is specific issue you have to focus more in your reading

\subsubsection{Afferent and Aesthetic Stance of Reading}

According to Arab bilinguals, people read basically for different reasons and different purposes. The first reason 
for reading is to gain new information (afferent stance) and second one is reading for pleasure (aesthetic stance). They also believe that reading is multifaceted process. They viewed reading as a lifelong process, and in its entirety people read the past and anticipate the future. What I realized is that all the interviewees viewed reading as receptive process "gain information", "gain knowledge", but none of them indicated as expressive process where you communicate what has been read by means of giving information and disseminate what you read. The following scripts from Khalid and Ali reflect that:

Khalid: People read for different things. But basically they read to get information of different kinds. They need this information to assemble an object or to pass an exam or get knowledge of some sort. So, people read when they search for some information, sometime this information can be inferring, sometimes they can be used for academic purposes sometime for joy and self-satisfaction and so force.

Ali: I guess people read to acquire knowledge, to know what around them, to know about the history, to know about the future, to explain the present, and to gain knowledge, and simply for fun as well.

\subsubsection{Good Readers as Avid and Fluent Readers}

A good reader according to Arabic bilinguals is the one who grasps and understands the context of what is being read and the one who finds pleasure in continuous reading, an avid and a fluent reader. For example, according to Maha and Azza, a good reader is "someone who reads fast and gets a lot of information in short time with optimal comprehension"; while Naser believes that "reading slowly and carefully with great understanding and thinking of what is read is what marks a good reader," Naser believes that "... reading without thinking is as drinking without tasting". Still another interviewee believes that a good reader is someone who has great vocabulary. Maybe the best interviewee who captured the definition of a good reader was Ali:

Ali: Well a good reader is a person who will be able to execute reading to its fullest benefits, that means he will get to the bottom of what he read; he will understand it as the author meant it to be, aaa to do this in timely manner, and excellent level of understanding in that given language. A good reader is one who read more often, and he will read aa a wide range of reading not just specialized in certain area, for instance, I don't consider someone who will confine all of his readings to certain area just a good reader, he is a good reader without a doubt, but a good or an excellent reader, is one who will be able to read .... in any field, and at least will come with the optimum understanding of that, and do this more regularly

Faisal: For a person to be a good reader, one needs to understand what he reads thoroughly and comprehends what he read completely.

Maha: A bad reader is someone who do not digest what he reads. Also, a bad reader does not use good strategies when he reads, and does not pay attention to what he reads.

\subsection{African Trilinguals' Views on Reading}

\subsubsection{Universal and Unitary View on Reading}

The three African trilinguals interviewees indicated a unitary and a universal view on reading. They regard reading as the ability to decode words with optimal understanding, reflection and communicating the ideas that was read. Moreover, they view their reading in three languages is the same activity. They also see the purpose of reading is to gain knowledge, learn about certain facts, understand, communicate, give information, and for pleasure as well. Basically, in their views people read for different reasons and different purposes. A good reader according to them, is the one who grasps and understands the context of what is being read, he is also someone who finds pleasure in continuous reading. The more he reads the more he wants to read more, and the more he becomes an avid reader. To become a good reader in any one of the language:

Imarou: One needs to know how to read for understanding, to know the text context and the meaning of words used in different languages.

Amadou: A person need to know the written language, I mean when you know the written language, know its rules-and read more in that language, the more you become a good reader in any language.

Mahamadou: A person needs to know how to decode words and understand the semantic, syntactic, and morphological aspects of the targeted languages.

\subsubsection{A good Reader has Metalinguistic Language Abilities}

For the trilinguals what constitutes a good reader is his abilities to navigate and try to relate to texts in different languages. He should possess metalinguistic abilities. As indicated by Imarou, Amadou and Mahamadou:

Imarou: A good reader understands and contemplates on the meanings of his or her reading in different 
languages, he or she also has sense of differentiating among different languages in conveying meaning, and hence there is no a single universal explanation of how people us rhetoric in different languages.

Amadou: The difference between a good reader and a poor reader is commitment and time. A good reader will create time and space to read more and study more. A good reader has also a commitment for reading in different languages and find some nuances among those languages; he or she has persistent longing for reading and knowing more in search for creative ways of conveying meaning.

Mahamadou: A good reader is more informed and more knowledgeable and someone who can interact with other languages and gain knowledge from these languages besides his first language or second language.

\subsection{The Reciprocity in Bilingualism}

Questions (6-11) dealt with reading in the two or more languages and reciprocal relationships between the two languages (i.e. Arabic and English; English, French and Hausa). The sixth question dealt with the difference between reading of bilinguals and monolingual, the seventh question dealt with whether knowing more than one language helps someone be a better reader or would it cause problems? and the eighth and the ninth questions investigated whether there is a gain from reading English when reading different languages. The tenth and eleventh questions tried to probe whether there is something learned in particular language to better understand English reading, and vice versa.

\subsubsection{The Superiority of Monolinguals over Bilinguals}

In responding to the difference that might exist between the reading of a person who is bilingual compared to someone who is monolingual. Arab Bilinguals believe that there is a great difference between their reading and the reading of monolinguals. They argued that monolinguals need less time to understand what they read, while bilingual need the double amount of time due to translation and checking meaning of words in dictionary. Translation is biggest problem for them because they might not attend to the same intended meaning; so, according to Khalid, Azza and Amir, nonnative speakers might not understand the intended meaning when they translate or if their guessing failed:

Khalid: Foreign language or a second language learners .... will encounter with what he doesn't know and therefore they may need to guess from their context and just live with the ambiguity... live with this ambiguity, because they are not sure about the meaning ... you know ... if they are not using the dictionary.

Azza: I think the big difference is that people who learn English as a second or foreign language sometimes they can have a problem, and I can see that in myself, umm like in translating sometimes when I read a text in English, I try to translated it ... umm .. in Arabic, and by translating word by word or a sentence by sentence, I could just miss the concept in English, so not like a person who just has only one language...is English, which let him only focus you know and think about the text only in one language, rather than thinking of it in two languages which could sometimes cause the problems, or lead you to miscomprehension or something like that. So, I would say a person who has learned English as second or foreign language may have some difficulties when he reads English.

Amir: To try to translate the sentence into the first language like if some who speaks Arabic he tries to translate the words into Arabic to understand it. Sometimes, it seems to be difficult because the meaning might change.

\subsubsection{Mismatch of Cultural Schemata}

Khaild, Azza, Ali and Amina, not only shared their views about how Arab bilinguals can get a wrong interpretation of meaning when they translate, they also believe that cultural schemata have great impact on what they read. They believe that bilinguals could come to misunderstanding due to the mismatch between the culture schema in both languages:

Khalid: Cultural background is necessary for reading English which can be immediately available to English native speakers and not for bilinguals

Azza: Especially if the aaa, and also like umm, if -if whatever is written in English, it has to do with the culture, I mean with the aa say - with the American culture, also that could be also a problem because that person can understand in a different way as long as he is coming from a different culture

Ali: I will say there is a great - a very great difference, native English speaker when he reads, he just reads in English, thinks in English, things will come very easy for him, and he will not have any problem in moving from one part, one idea in the text to another idea, while a person who reads in English and English is his second language or third language, probably he might stumble a little bit when he is reading, probably he will try to think in another language, to read in a language and think in another language, this might interrupt the flow of 
the ideas in what he is reading, and not to mention if he is not having a good command of the second language, so there is a great difference.

Amina: "I believe that the first language is the language that you think in. It does not matter what language you learnt first. How often you use a language is a major factor in which language becomes your first language. When I read in English, the words are translated into Arabic in my head to understand what I am reading.

Arabic as a Base for Subsequent Language Literacy

Seven of the of Arabic bilinguals indicated that being able to read in Arabic helps when they start reading in English. Those who indicated that Arabic helps them when they read English basically believe Arabic as their first language was the base for their subsequent literacy in their second language English.

Amina: Yes, it helps. I translate what I read in English into Arabic in my head when I don't understand it in English.

Naser: Yes, since Arabic has more sounds and meanings than English

Ali: Yes, I will say learning Arabic- knowing Arabic language helps me to a great extent in reading English.

Khalid: Yes, sometimes when the same piece of information is available in the two languages I think it is clarifying. I think the academic style ... you know ... sometimes is the same. So, I think this the only case where Arabic can help reading English."

\subsubsection{Arabic and English: Irreconcilable Linguistics Proximity}

In responding to the question of whether knowing more than one language helps someone be a better reader or would it cause problems? Arab Bilinguals' views varied between those who believe knowing more than one language is a source of confusion, and those who believe that it is an advantage to learn another language with similar orthography such as French. The first group represented by Mahmoud, Amina, and Samir who emphasized that knowing more than one language causes confusion because bilinguals tried to understand a second language through their first language, and here are some examples of what they said:

Mahmoud: Sometimes, it does cause some problem in term of mixing and trying to understand the second language through the first language, what I am trying to say second language learners always try to translate the sentence into his original language

Amina: It causes problems because knowing more than one language affects your perfection in each language

Samir: I don't think it helps in being a good reader, however it increases the enthusiasm of that person to learn in their own language. For example, I myself starts to pay attention for my own language and learn more words and to increase my Arabic vocabulary when you use the dictionary you will see some words which you never used

\subsubsection{Arabic and English: Dealing with Orthographic Difference}

Some of the Arab bilinguals such as Khalid, Amir and Ali believed that knowing similar languages with same orthography such as French, Spanish and English could help to be a better reader but not different languages without orthographic similarities such as English, Arabic or Chinese. Azza and Maha drew from their little experience with learning some French which they think bear similarities to English, while Khalid mentioned some experiences of some friends who speak French which facilitate their English reading.

Khalid: I don't not see any connection between reading in Arabic and in English, so I believe no help in that.

Azza: I am not sure if English could help me when I read in Arabic, I am not really sure that could help me, but that could happen, reading English and French, they have similar words and here I can see how it can help but Arabic I don't think so. I don't think English helps me when I read in Arabic.

Amir: No. It doesn't make any difference I think Arabic is Arabic and English is English unless the use of English terminologies in Arabic ....so I didn't see any relation.

Ali: "You see probably, it should help, but maybe personally, in my experience, it didn't help me much.

\subsubsection{Reciprocity in Trilingualism}

\subsubsection{Superiority of Monolinguals}

The African trilinguals: Imarou, Amadou: Mahamadou indicated some differences between monolingual and bilingual. According to Imarou: "those differences depends on the level of education and personal interest in what is read", while Mahamadou believes that the only difference is the "accent". For Mahamadou, native speakers have a lot advantages than bilinguals and trilinguals because native speaker read, listen, write and speak 
more often than trilinguals. So, they are in the full-command of their language. They also viewed believed that:

Imarou: It depends on the ability of the individual in switching from one language to another. For me, know many languages beside English as a third language, only helps me to be a better reader.

Amadou: Knowing more than one language is very helpful. But it can also cause some problems because you may jump from one language to another.

Mahamadou: I have two views on this, first: people who speak more than one language have advantages of interacting with different languages, different world-views, different ideas, and different cultures and they can share their culture with others, so they have better understanding than monglinguals, second there is a little problem nonnative speakers have which is the translation, sometime you cannot find the same meaning between two languages, so you just try to accommodate the different meanings.

\subsection{Strategic Learning and Consideration of Bilingualism}

The twelfth question dealt with translation from one language to the other, the thirteenth question asked about the language that Arabic bilinguals and African trilinguals feel more comfortable to read in, the fourteenth question dealt with whether there are some subjects (e.g., math or science) that Arabic Bilinguals and African multilinguals feel more comfortable to read in one language than the other, and the last question was an open question. So, Arabic bilinguals and African multilinguals could share anything about reading in bilingually or multilingually.

\subsubsection{Arab Bilinguals and the Partial Strategies Transfer}

Arab bilinguals were also asked about whether they have ever learned how to do something to better understand their English reading that they later used when reading Arabic, and vice versa. Most of the Arab bilinguals indicated that they don't use the same strategies when they read in both languages, or they don't transfer what they learned in English to Arabic.

Amin: No, I never used the same procedure when reading in English as in Arabic, I used to have a dictionary next to me whenever I am reading in English. This increased my vocabulary. But, I never use this technique when I read in Arabic.

Ali: No. no in fact in reading English I used some strategies just like underline certain areas or highlight them or to try to pick certain areas of interest to the understanding but nevertheless those strategies to me are very helpful and very powerful in learning English.... in reading English I never used them in Arabic. I just did not feel the need for it in Arabic. Probably I will say so I am very proficient in Arabic language.

Faisal: There is no connection between the two languages. So you have to learn each language independently."

Few of Arab bilinguals indicated that they use some of strategies in reading English that they use when they read in Arabic, such strategies like getting the main idea, rereading for better understanding, and taking notes, seemed to transfer from English to Arabic.

Khalid: I think using key words while reading in English this strategy seems to work very well. So, sometimes I tried to do that in Arabic without much reading you know in many years Arabic but this strategy seems to transfer also to Arabic text.

Azza: Well I think I did, ... umm ... when I came here, and you know- and I started school, when I was reading English sometimes I was not able to understand the text, so I try to write down, usually when I was learning in Arabic I did not do that, I try to repeat reading - you know - to talk to my self-aloud, to understand the things, and when I want to memorize things usually I just underline it. Now in reading English I did something which was new to me, and I think I could also use when I read Arabic.

Maha: When I started learning English, I used to read slow and try to reread every sentence I didn't understand so as to get a better understanding. Later on, when I didn't read in Arabic for a while, and when I read something and I don't understand I reread it again.

Very few of Arab bilinguals indicated a transfer of strategies from Arabic to English and this came as a surprise to me.

\subsubsection{Translation is a Step to Fluency}

Arabic bilinguals indicated that they translated from English into Arabic. But translation to them is two sword edges. For example, some believed it took them far from the intended meaning, still some indicated that they used to translate when their English language was weak compared to Arabic, but when they reached a certain competency in English language translation faded away. Their responses indicated that translation is phase of 
language development, it was triggered when the need arises, otherwise it will stay dormant.

Mahmoud: Yes, I did, sometimes I go away from the real meaning of the sentence or the statement because I try to translate into Arabic word by word, which will not help.

Amina: Yes, I do when I am reading in English, I think in English until I read something that I don't understand and that is when I try to translate it into Arabic in my head to better understand it.

Khalid: I do translate for academic and educational purposes but I never translate to understand my readings maybe at some points when I am an undergraduate student but that was 12 years ago.

Azza: Yes, I do translate from English into my native language Arabic, in fact not most of the time, if the text is easy for me to understand in English, I don't usually translate it, but if the text for me is hard to understand, or there is umm, -you know- I feel like it is not easy for me to go through the text, I usually try to translate it to myself in Arabic, and sometimes even word by word or sentence by sentence to figure it out.

\subsubsection{Arab bilinguals Feel at Ease in Reading Arabic}

The language that Arab bilinguals felt most comfortable when they read is Arabic; but for those who reach certain competency in English, they consider English and Arabic are about the same.

Mahmoud: I feel more comfortable when I read in Arabic.

Naser: Without a doubt, I feel more comfortable when I read in Arabic

Maha: When I read in Arabic I feel more comfortable than when I read in English. Unfortunately, I don't have the time to read in Arabic every day.

Azza: I feel more comfortable in fact when I read in Arabic, and sometimes also I have the same feeling when I read in English, and it depends on what I am reading in fact.

Math and science are languages of their own territory, math and science came with their own symbols, Arab bilinguals even when they studied in Arabic, they have to expose to Latin and Greek symbols and terminologies which come through either English or French. This is true especially for those who have science and engineering as their majors, they exposed to math and science in European languages more often than those in arts and humanities. Arabic native speakers, especially those who came from engineering or science domains indicted that they preferred to read and do science and math in English, since the terminologies were first taught to them through English. On the other hand, those who studied arts, social science and humanities preferred those subjects in Arabic.

Mahmoud: I prefer to read science in general and math in English and I would say I cannot understand these topics in Arabic at all because I did learn most of them in English and practice them in English and if I try to read or to solve some equations in Arabic I will be so confused.

Amina: I'm much more comfortable reading about math and science in English rather than in Arabic.

Naser: Some science topics and expressions I like to read them in English while I still prefer and will get more benefits and in less time if I read in Arabic. Mainly the scientific expressions that I prefer using English in it since I knew it as is in English first.

Those who did not expose to science and math excessively in English, and those are usually in liberal arts, social science and humanities in general, they indicated that they preferred Arabic to read math and science.

Samir: Ya most probably, I think as the way you used to if you used to study math in English it will be easier for you in English. If you learn science in English will be easier in English because the symbols you used to and the definitions and the scientific terms facilitate the reading in that language in particular.

Azza: I will say yes, umm I will prefer to read math in Arabic because, maybe because the terminologies, the mathematics terminologies I learned them -you know- in the first place in Arabic language.

Khalid: Mm I haven't feel reading math or science books but I do like reading scientific books and pure science in both Arabic first or English second... maybe because I came from liberal arts background.

The thing that Arab bilinguals shared with me about their reading in two languages is the fear to lose their first language, and at the time to maintain a high proficiency in their second language. This fear is rooted in their trial to strike a balance between the two languages.

Amina: When a person knows more than one language, one will affect the other and one will be stronger than the other depending on how often it is used, no matter what the native language is. How much you use the language will affect your proficiency in that language and the first language can be replaced by another language. 
Khalid: Ah, the problem I think is when you start learning another language and/or doing a graduate study in aa second language your reading in your first language are reduced and this comparison may not hold sometimes, but and even in some specialties this continue even when you go back to your country ok, coming from an English major I think most of studies I am going to read is going to be in an English most of the classes I am going to teach are going to be in English so I am not sure but I think I am lagging behind in term of the number of texts I am reading in Arabic. I hope to do some more readings in Arabic when I come back go back to my native country and that what I guess.

Samir: I think it not easy thing to master a foreign language. You see it was even for me very difficult to master my Arabic language. Therefore, for mastering English language it will be more difficult and it will take more time and it needs more effort to master it

Still another interviewee indicated that reading in two languages is a unique experience, which added to his repertoire of knowledge:

Ali: I wish if I can read in more than two languages. I think it will be a very rich experience to read in two languages and it will be much rich if you can read in more than two or three or four languages, but for me reading in two languages this open to me another opportunity, another school of thought in the other language and gave me access to all the jewels of both languages, so this is a very rich experience and I hope a lot of people to enjoy that and to improve on that.

\subsubsection{The Effects of Later Literacy on the Primary Literacies and Vice Versa}

For Osman, Khalidou, and Amadou English enhances their reading skills, especially in a relatively similar language as French, but not Hausa, they believe that English and French have many things in common because they share a Latin source which feature many cognates, but Hausa does not have any similarities with those languages. On the other hand, they believe their primary literacies (French and Hausa) established a good foundation for learning English, because they are "the base" from which they define what a language is, and how it functions. They consider their first and second languages the key for all other languages.

\subsubsection{What is Learned from Language(s) to Others?}

Osman, Khalidou, and Amadou believed that language have reciprocal effects on each other, they learned some strategies in their third languages (English) that they often apply to their first and second language. They also believe that the first and second language are the base for developing some strategies that were transfer later on when they start reading in their third language, some strategies like how to use a dictionary, looking for the meaning from the context, and etc.

\subsubsection{Limited Translation from English to Others}

Osman: No. I think and write in any of the three languages when I am using them.

Khalidou: I don't translate at all from English to French or Hausa.

Amadou: Yes, I sometimes translate from Hausa and French when reading English. It was confusing for the first time. Then when you understand the meaning of the words in both languages it became easier to translate.

For Osman, Khalidou, and Amadou, the language they feel more comfortable when they read is same language(s) they feel to do math and science and nature in general, for example Osman feels more comfortable to read in English and French and do science and math in English and French, Khalidou he feels more comfortable to read in English and to do math and science in English as well. For Amadou the language he feels more comfortable to read in is French and do math and science in French as well

\subsubsection{Multiliteracy and Multilanguage Competence}

Osman: It is the fact that learning and using many languages makes me a better reader in the languages. I am very careful in making silly grammatical mistakes many people make even those who speak English as a first language.

Khalidou: I think reading in three languages is fun. You can drive from different sources, and know more cultures and different ideas and point of views. I believe this experience makes you also more flexible in your judgment about those cultures, because every culture has its values and traditions which embedded in its language.

Amadou: I think each language represents a culture, so being able to understand a lot of cultures at the same time gives you more knowledge and more space to live and understand. 


\subsection{Summary of Major Findings}

Arab bilinguals and African multilinguals' views on reading

We can glean from those interviews that the ten Arab bilingual have different views than those of the three African trilinguals on reading. In general, the Arab bilinguals viewed reading in terms of meaning making, gaining some factual data, from certain contexts in order to reflect upon it, whereas, the three trilinguals viewed reading from a wider perspective. Namely, the trilinguals viewed reading as communicative act in order to disseminate some information in a wider spatial perspective in a trilingual fashion; all the gained information is contested in a continuous and multicultural way gleaned from their acquisition and learning three or more languages (see Figure 1 and 2).

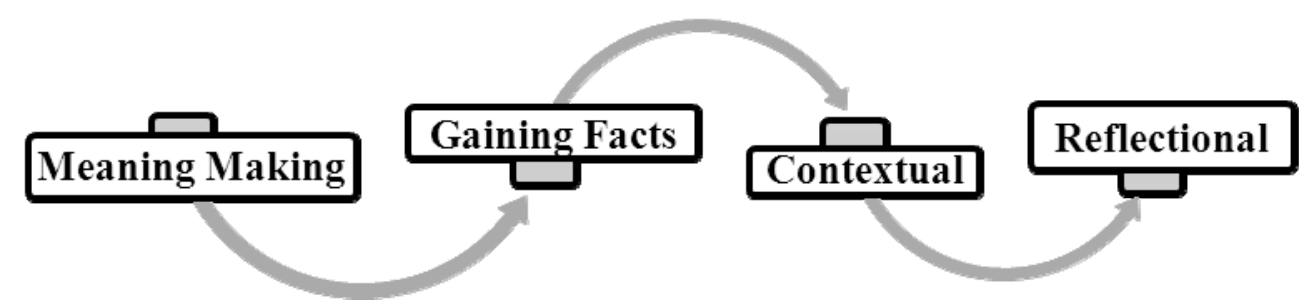

Figure 1. Arab bilinguals' views on reading $(n=10)$

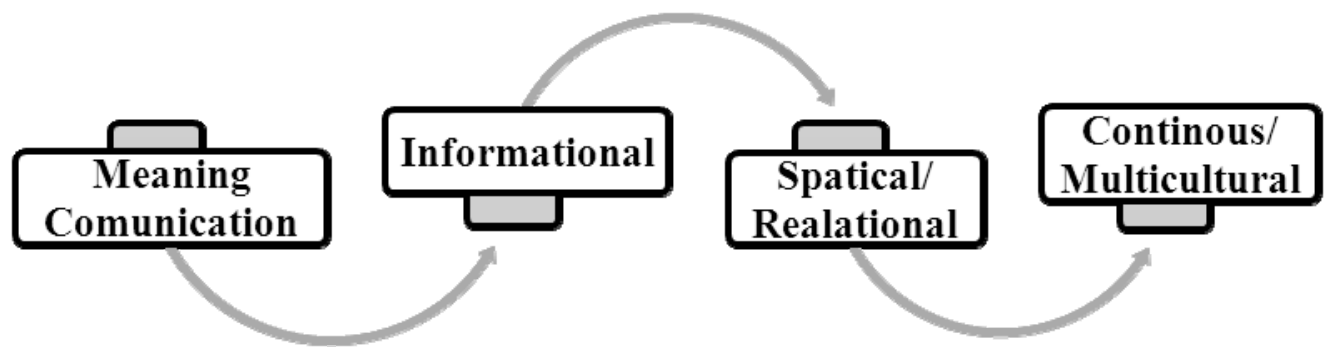

Figure 2. African multilinguals' views on reading $(n=3)$

\subsection{The Arab Bilinguals and African Trilinguals on Language Learning}

We can glean from those interviews that the ten Arab bilingual and the three African trilinguals have some similarities and some differences on their view of their language learning. Both bilinguals and multilinguals agreed on the advantageous position of monolinguals on language learning but their views on other aspects of language learning vary. From the Arab bilinguals' vantage point, learning another language could be a subtractive process, they indicated also linguistic complexity between Arabic and English, they indicated linguistic differences, where there are no linguistic similarities where Arabic has a marked distinctive features such as its writing system and syntactic structure which makes it different from English; they also indicated some selected strategies that could be transfer to English. On the other hand, multilinguals see their multilingualism is an asset of an additive bilingualism, linguistic clarity due to their exposure to different linguistic systems; there are some linguistic similarities between romance languages such as French and English, and some difference among English, French and Hausa; they also indicated more strategies transfer acquired through dealing with different language systems; they also indicated limited translation among languages (See Table 1 below). 
Table 1. The Arab bilinguals and African Trilinguals on language learning

\begin{tabular}{|c|c|c|}
\hline & Arab Bilinguals & African Trilinguals \\
\hline Language & 1. Advantage of Monolinguals & 1. Advantage of Monolinguals \\
\hline \multirow[t]{2}{*}{ Learning } & 2. Subtractive Bilingualism & 2. Additive Bilingualism \\
\hline & 3. Linguistic Complexity & 3. Linguistic Clarity \\
\hline \multirow[t]{3}{*}{ Languages Reciprocity } & 1. Metalinguistic Obstacles & 1. Metalinguistic Opportunities \\
\hline & 2. Double Language Perspectives & 2. Multiple Language Perspectives \\
\hline & 3. Linguistic Difference & 3. Linguistic Similarities \\
\hline \multirow[t]{2}{*}{ Strategies Transfer } & 1. Selected Strategies Transfer & 1. Unlimited Strategies Transfer \\
\hline & 2. More translation & 2. Less translation \\
\hline
\end{tabular}

\section{Discussion}

The underlying premises of this study is that the bilingual and multilinguals usually carry meaningful views towards the languages they acquired and learnt, their perceptions about the confines, borders and boundaries between and among languages are so important and vital on how they view the languages they acquired and learnt. It is vital to meditate and negotiate their metalinguistic stances which could open some venues for us to reach a transcendental understanding of the languages they learned and the different realities they establish (Hadi-Tabassum, 2006). Some researchers indicated that research in trilingualism is carried out in the theoretical vein of bilingualism and there are no real efforts to delimit trilingualism in its own right (Aronin, \& Hufeisen, 2009; Hoffmann, 2001; Njurai, 2016). Although certain salient similar features could be noticed in both bilinguals and trilinguals (Aronin \& Hufeisen, 2009) there are some distinct features that could be observed in trilingualism as it was evident in this study.

The findings of this study revealed that there are some distinct features that distinguish bilinguals from multilinguals in terms of their reading habits and language learning. For example, the Arab bilinguals in this study viewed reading in terms of meaning generating, searching for facts based on certain contexts in order to reflect upon it; whereas the trilinguals viewed reading from a wider perspective when they looked upon reading as communicative act in order to disseminate some information in a wider spatial perspective multilingually, all the gained information according to trilinguals is contested in a continuous and a multicultural disposition gleaned from their acquisition and learning three or more languages.

In this study the bilinguals and trilinguals' views reflected the findings of Grosjean (1982) in that there was "no inconvenience" in being bilinguals" or "trilinguals". Albeit, their agreement of the superiority of the monolinguals, there are some differences in viewing their language learning. From the Arab bilinguals' perspectives learning another language could be a subtractive process, they indicated linguistic complexity between Arabic and English, they pointed to linguistic differences, they also indicated some selected strategies that could be transfer to English and they actually translate from English to Arabic (see Alsheikh, 2014; Alsheikh \& Mokhtari, 2011; Alsheikh, 2009)). On the other hand, the three African multilinguals see their multilingualism as an asset of an additive bilingualism, linguistic clarity due to their exposure to different linguistic systems; they indicated that there are some linguistic similarities between romance languages such as French and English language; they also pointed there are some differences among English, French and Hausa; they also pointed to more strategies transfer than the bilinguals which corroborated findings from Alsheikh (2011). The striking differences among bilinguals and trilinguals validated earlier findings from Grosjean (1982) who pointed to some advantages of bilinguality such as: communication and bond with other bilinguals, communicating with two cultures, give double perspectives on the world, communicate with more people. The multilinguals see the advantage as: broaden their human scope, communicate with different types of people, read a greater variety of books, each language has different logic, aware of linguistic problems, add different manner and means of expressions, see the beauty of languages, add spatial spectrum in human experience, no boredom, open mindedness, personal pride, greater stature in work and job opportunities (see pp. 268-272).

This views are very close to what Bakhtin described as a heteroglossia. A Heteroglossia is "a way of conceiving the world as made up of a rolling mass of languages, each of which has its own distinct formal markers" (Holquist, 1990, p. 69). Although Bakhtin focused on first language dialogic principles, this description fit perfectly with bilinguals and trilinguals. In essence, Bakhtin's view is similar to what bilinguals in general and 
trilinguals in particular try to achieve when they read in a second, a third or a fourth language. They usually try to make sense of their reading in that language and they become very attentive to the act of reading. In a very important sense, the three multilinguals in this study dealt with learning and reading in different languages by capitalizing on their heteroglossic repertoire. Although, heteroglossia as described by Bakhtin (1934) confined itself to the coexistence of distinct varieties within a single language, the multilinguals' transcendental abilities juxtapose myriad responses by connecting different languages as unitary language and deal with it as metalinguistic tapestry framed in different Discourse(s) selected from the teeming thousands available (Alsheikh, 2011; Holquist, 1990).

\section{References}

Alsheikh, N. (2014). The perceived and actual use of metacognitive reading strategies by the UAE high school students, Journal of ELT and Applied Linguistics (JELTAL), 2(1), 140-153.

Alsheikh, N., \& Mokhtari, K. (2011). An Examination of the Metacognitive Reading Strategies Used by Native Speakers of Arabic when Reading Academic Texts in Arabic and English. English Language Teaching, 4(2), 151-160. https://doi.org/10.5539/elt.v4n2p151

Alsheikh, N. (2011). Three readers, three languages, three texts: The Strategic reading of multilingual and multiliterate readers. The Reading Matrix, 11(1), 34-53.

Alsheikh, N. (2009). The strategic reading of native speakers of Arabic. VDM Verlag Publisher, Germany.

Aronin, L., \& Hufeisen, B. (2009). The Exploration of Multilingualism: Development of research on L3, multilingualism and multiple language acquisition, John Benjamins Publishing Company, Philadelphia, PA. https://doi.org/10.1075/aals.6

Bernard, H., R., \& Ryan, G. W. (2010). Analyzing Qualitative Data: Systematic Approaches. Thousand Oaks, CA: Sage Publications.

Bialystok, E. (2001). Bilingualism in development: Language, literacy, and cognition. New York: Cambridge University Press. https://doi.org/10.1017/CBO9780511605963

Blumer, H. (1986). Symbolic Interactionism: Perspective and Method. University of California Press; Berkeley Los Angeles, CA.

Carroll, J. (ed.) (1956). Language, Thought, and Reality: Selected Writings of Benjamin Lee Whorf. Cambridge, Mass.: Technology Press of Massachusetts Institute of Technology. https://doi.org/10.5840/thought1956/195731493

Garcia, E. G. (1991). Factors influencing the Spanish reading test performance of Spanish-speaking Hispanic children. Reading Research Quarterly, 26, 371-392. https://doi.org/10.2307/747894

Garner, R. (1980). Monitoring of understanding: An investigation of good and poor readers' awareness of induced miscomprehension of text. Journal of Reading Behavior, 12, 55-63. https://doi.org/10.1080/10862968009547352

Garner, R. (1987). Metacognition and Comprehension. Norwood, New Jersey: Ablex Publishing Corporation.

Grosjean, F. (1982). Life with two languages: An Introduction to Bilingualism, Cambridge, MA: Harvard University Press.

Grosjean, F. (1989). Neurolinguists, beware! The bilingual is not two monolinguals in one person, Brain and Language, 36(1), 3-15. https://doi.org/10.1016/0093-934X(89)90048-5

García, O., \& Lin, A. (2016). Extending understandings of bilingual and multilingual education. In O. García, A. Lin, \& S. May (Eds.). Bilingual Education (Vol. 5, pp. 1-20). Encyclopedia of Language and Education, Springer. https://doi.org/10.1007/978-3-319-02324-3_1-1

Hadi-Tabassum, S. (2006). Language, space and power: A critical look at bilingual education, Clevedon, Multlingual Matters.

Holquist, M. (1990). Dialogism: Bakhtin and his world. New York. NY: Routledge. https://doi.org/10.4324/9780203330340

Hakuta K. (2011). Educating language minority students and affirming their equal tights: Research and Practical Perspectives. Educational Researcher, 40(4), 163-174. https://doi.org/10.3102/0013189X11404943

Hoffmann, C. (2001). Towards a description of trilingual competence. International Journal of Bilingualism, 5(1), 1-17. https://doi.org/10.1177/13670069010050010101 
Jimenez, R., Garcia, G., \& Pearson, P. (1996). The reading strategies of bilingual Latina/o students who are successful English readers: Opportunities and obstacles. Reading Research Quarterly, 31, 90-112. https://doi.org/10.1598/RRQ.31.1.5

Jimenez, R., Garcia, C., \& Pearson, P. (1995). Three children, two languages, and strategic reading: Case studies in bilingual/monolingual reading. American Educational Research Journal, 32(1), 67-97. https://doi.org/10.3102/00028312032001067

Jimenez, R., Garcia, G., \& Pearson, P. (1994). The metacognitive strategies of Latina/o students who read Spanish and English, Technical Report \# 601. Urbana-Champagne, IL: University of Illinois, Center for the Study of Reading.

Kvale, S. (1996). Interviews: An introduction to qualitative research interviewing. Thousand Oaks, Sage Publications, CA.

Kvale, S. (2008). Doing Interviews, Thousand Oaks, CA: Sage Publication Ltd.

Kvale, S., \& Brinkmann, S. (2009). InterViews: Learning the craft of qualitative research Interviewing (2nd Ed.). Sage Publications Inc., Thousand Oaks, California.

Lvovich, N. (1997). The multilingual self: An inquiry into language learning. Lawrence Erlbaum Associates, Publishers, Mahwah, New Jersey.

Njurai, E. W. (2016). Language practices involving two languages among trilingual undergraduate students of Mathematics. IMHOTEP: African Journal of Pure and Applied Mathematics, 3(1), 45-68.

Pavlenko, A. (2006). Bilingual Minds: Emotional Experience, Expression and Representation. Buffalo, NY, Multilingual Matters LTD.

Pavlenko, A. (2005). Emotions and multilingualism. New York: Cambridge University Press.

Peal, E., \& Lambert, W. E. (1962). The relation of bilingualism to intelligence. Psychological Monographs: General and Applied, 27(546), 1-23. https://doi.org/10.1037/h0093840

Pease-Alvarez, L., \& Hakuta K. (1992) Enriching our views of bilingualism and bilingual education. Educational Researcher, 21(2), 4-19. https://doi.org/10.3102/0013189X021002004

Pease-Alvarez L. (2002). Moving beyond linear trajectories of language shift and bilingual language socialization. Hispanic Journal of Behavioral Sciences, 24(2), 114-137. https://doi.org/10.1177/0739986302024002002

Prus, R. (1996). Symbolic interaction and ethnographic research: Intersubjectivity and the study of human lived experience. State University of New York, Albany, NY.

Whorf, B. (1940a). Science and linguistics. Technology Review, 42(6), 229-231, 247-248. Reprinted in Whorf, B. (2012). Language, thought, and reality: Selected writings of Benjamin Lee Whorf. 2nd ed. In J. Carroll, S. Levinson, \& P. Lee (Eds.) (pp. 265-280). Cambridge, MA: MIT Press.

\section{Copyrights}

Copyright for this article is retained by the author(s), with first publication rights granted to the journal.

This is an open-access article distributed under the terms and conditions of the Creative Commons Attribution license (http://creativecommons.org/licenses/by/4.0/). 